\title{
Aprendiendo liderazgo y trabajo en equipo mediante el juego fuera del aula
}

\author{
María de-Miguel-Molina ${ }^{a}$, Daniel Catalá-Pérez ${ }^{\mathrm{b}}$, Virginia Santamarina-Campos ${ }^{\mathfrak{c}}$ y \\ María Ángeles Carabal-Montagud ${ }^{\mathrm{d}}$ \\ anniversitat Politècnica de València, mademi@omp.upv.es, bUniversitat Politècnica de València, \\ dacapre@ade.upv.es, 'Universitat Politècnica de València, virsanca@crbc.upv.es y dUniversitat \\ Politècnica de València, macamon@crbc.upv.es
}

\begin{abstract}
The aim of this group dynamic was that the students "learn by doing" through an outside classroom activity, proposed like a game. The activity was included in the topic "Leadership and groups management" and we planned it in two phases: a first one "outside the classroom" and a second one in the classroom, to reflect on and report the activity. The results were quite positive because, more than learning to solve a challenge in a creative way, the students realized how they had unconsciously taken decisions quickly, more or less accurate, and, in the following analysis, they could find which mistakes could have been avoided with a previous management knowledge.
\end{abstract}

Keywords: leadership, team working, outside classroom activity, gaming, creativity.

\begin{abstract}
Resumen
El objetivo de esta dinámica de grupo fue que los alumnos "aprendiesen haciendo" mediante una actividad fuera del aula, planteada como un juego. La actividad estaba enmarcada en el tema "Liderazgo y gestión de grupos" y se desarrolló en dos fases: una primera fase "fuera del aula" y una segunda fase en el aula, de reflexión y elaboración de un informe sobre esta actividad. Los resultados fueron muy positivos porque, además de aprender a resolver un reto de manera creativa, los alumnos se dieron cuenta de cómo inconscientemente tomaron decisiones de manera rápida, con más o menos acierto, y en la reflexión posterior pudieron detectar qué fallos se podrían haber evitado con unos conocimientos previos de gestión.
\end{abstract}

Palabras clave: liderazgo, trabajo en equipo, actividad fuera del aula, juego, creatividad. 


\section{Introducción}

Las actividades en equipo fuera del aula permiten a los alumnos entrar en contacto con posibles situaciones futuras, potenciando además el desarrollo de sus capacidades de comunicación, la participación activa, la creatividad y, por tanto, la adquisición de distintas competencias transversales (Carabal et al, 2018). Entre estas competencias transversales, podemos encontrar (Universitat Politècnica de València, 2019): aplicación y pensamiento práctico (CT2), análisis y resolución de problemas (CT3), creatividad (CT4), trabajo en equipo y liderazgo (CT6), planificación y gestión del tiempo (CT12).

Además, por otro lado, el juego se ha mostrado muchas veces como una actividad eficaz para obtener resultados de aprendizaje (De Miguel et al, 2015). Con el "juego serio" se puede conseguir una reflexión crítica sobre un reto (Hinthorne y Schneider, 2012). Las ventajas del juego para aprender son resumidas por Linder et al. (2001) en: conseguir interrelación social, favorecer la expresión emocional, aumentar el desarrollo cognitivo y estimular la competencia. Fernández Solo de Zaldívar (2015), añade a estas ventajas del juego la posibilidad de tomar decisiones y correr riesgos en un entorno protegido, a la vez que se desarrollan habilidades como la intuición, rapidez o empatía, de forma que el juego se convierte en una forma de aprender haciendo. Por todo ello, nos planteamos la posibilidad de reunir ambos conceptos en una práctica de aula, donde los alumnos pudiesen beneficiarse de ese "juego serio" pero fuera del aula, potenciando todavía más las distintas competencias transversales a la vez que aprendiesen unos conocimientos concretos.

\section{Objetivos}

El objetivo principal de la dinámica fue que los alumnos aprendiesen haciendo, y para ello se les planteó una dinámica fuera del aula en la que pudiesen aplicar el liderazgo y trabajo en equipo. Además, la dinámica se planteó como un juego de manera que el equipo que mejor resolviese el reto fuese gratificado (en este caso, se les asignaba medio punto extra en la práctica).

Por otro lado, los objetivos específicos de aprendizaje se basaron en las siguientes preguntas:

- ¿Qué diferencia a un grupo de un equipo de trabajo?

- ¿Existen características que contribuyen a hacer eficaces a los equipos de trabajo?

La dinámica, con modificaciones, se realiza en los entrenamientos de algunos Cuerpos de Seguridad del Estado que se dedican a investigación, por lo que conocíamos que era una actividad efectiva para resolver retos. En cualquier caso, nosotros la ajustamos al tiempo que teníamos para ello.

La práctica estaba relacionada con el tema "Liderazgo y gestión de grupos" de la asignatura Dirección Estratégica de Organizaciones Públicas (De Miguel et al, 2017), obligatoria de $3^{\circ}$ curso, del Grado en Gestión y Administración Pública de la Facultad de Administración y Dirección de Empresas de la Universitat Politècnica de València (UPV). Asimismo, está 
enmarcada dentro del Equipo de Innovación y Mejora Educativa (EICE) "El proceso de Enseñanza y Aprendizaje Fuera de las Aulas", liderado por la profesora Santamarina, en el que participan profesores de otros centros de la UPV con los que trabajamos estas dinámicas.

\section{Desarrollo de la innovación}

La actividad se realizó en una de las sesiones de práctica de aula, tanto en el grupo de mañana como en el de tarde, donde los alumnos disponían de dos horas para realizar la fase fuera del aula y la fase dentro del aula. Para la primera fase, nos teníamos que limitar al Campus de Vera ya que de lo contrario no hubiesen tenido tiempo suficiente.

El reto que se les planteó fue encontrar un elemento dentro del Campus de Vera de la UPV. En cada grupo, mañana y tarde, el elemento cambiaba para evitar que lo supieran de antemano. Cada grupo tiene alrededor de 30 alumnos.

Las fases que se siguieron en la actividad fuera del aula fueron las siguientes:

1. Se mostró el lugar/objeto que tenían que encontrar (Imágenes 1 y 2).
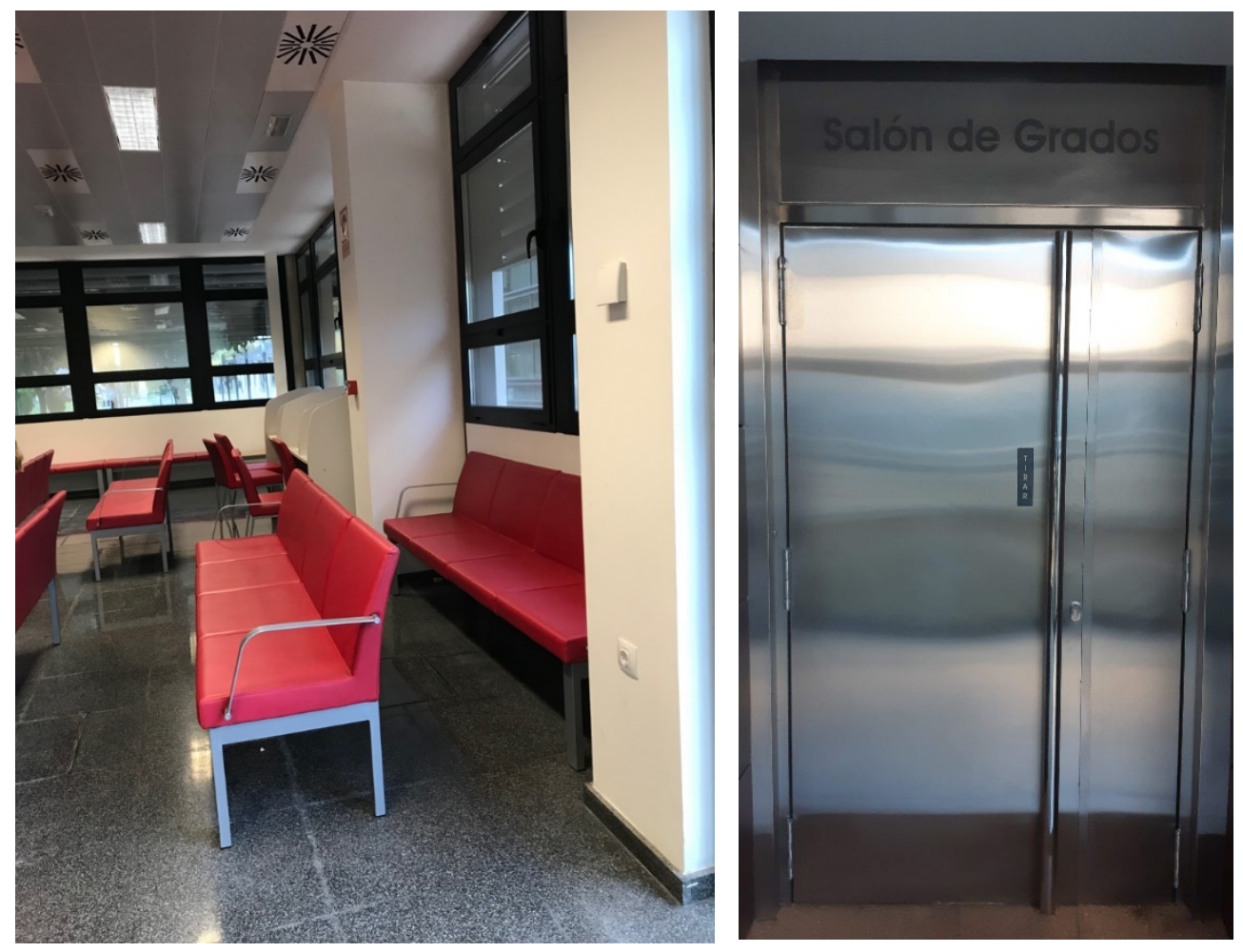

Imágenes 1 y 2 Espacios a localizar. Fuente: elaboración propia. 
2. Se formaron los equipos (entre 3-6 alumnos por equipo).

3. Los equipos se organizaron para encontrar el lugar (Imágenes 1 y 2) en 1 hora de tiempo como máximo. Los equipos no recibieron ninguna indicación acerca de como debían proceder en la búsqueda del lugar/objeto. Se les dio libertad a la hora de organizar dicha búsqueda. El profesor no les acompañaba, sino que se quedó en el aula para esperar al equipo que completase el reto en primer lugar.

4. Localización y registro fotográfico por el equipo, como prueba de que se había localizado correctamente el lugar que se buscaba.

5. Vuelta al aula.

Una vez todos los equipos habían llegado al aula, en la siguiente hora cada equipo hizo un análisis de la dinámica y un informe, donde se explicase:

a. ¿Quién ha ejercido de líder? ¿Se ha elegido o ha surgido de manera natural?

b. ¿Cómo os habéis organizado? ¿Todos los integrantes del equipo han colaborado de la misma manera?

c. Explicar el método SMART con la actividad que se ha realizado (Figura 1). Este método (Druker 1954/2006) propone una método de asignación de tareas en: específicas (Specific), medibles (Measurable), factibles (Achievable), realistas (Realistic) y especificadas en el tiempo (Time-related).

d. ¿Ha habido algún conflicto? ¿Se ha resuelto? ¿Cómo?

e. Si repitiérais la actividad, ¿hubiéseis cambiado algo?

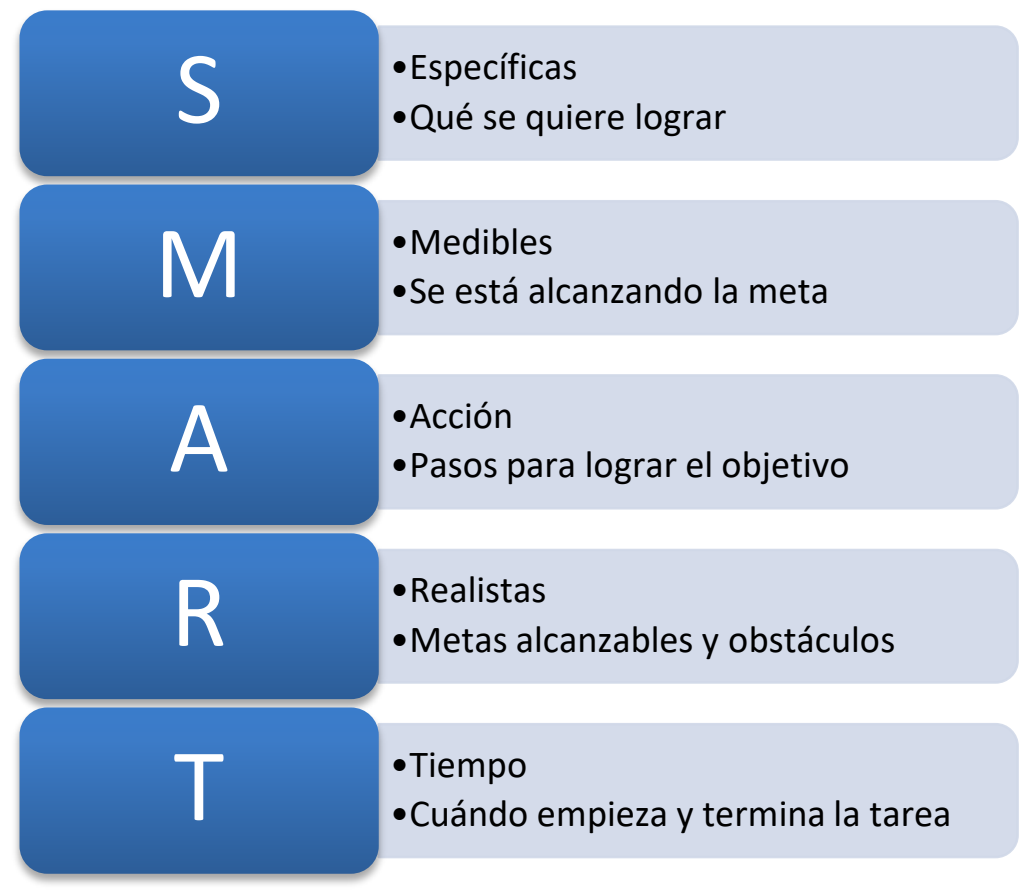

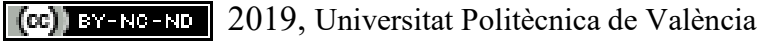


Finalizado el informe, el profesor analizó los resultados de todos los equipos y abrió un debate sobre qué cosas se hubiesen hecho de manera diferente.

\section{Resultados}

Tanto en el grupo de mañana como en el de tarde, se formaron unos 7-8 equipos. Revisando las preguntas que contestaron en el informe, podemos sacar algunos puntos en común y otros en los que hubo diversidad.

a. ¿Quién ha ejercido de líder? ¿Se ha elegido o ha surgido de manera natural?

En todos los equipos el liderazgo surgió de manera natural.

b. ¿Cómo os habéis organizado? ¿Todos los integrantes del equipo han colaborado de la misma manera?

Mientras algunos equipos se organizaron y dividieron las tareas para lograr mejor el objetivo, en otros casos no hubo división de tareas. En general, los grupos más creativos a la hora de organizar el trabajo lograron completar el objetivo antes que el resto. Por ejemplo, algunos crearon grupos de whatsapp para comunicarse. En este sentido, para el equipo ganador del grupo de la mañana, por ejemplo, además de dividirse las tareas, fueron fundamentales ciertos recursos disponibles como el uso de bicicletas para desplazarse por el campus.

c. Explicar el método SMART con la actividad que se ha realizado.

Específicas: todos tuvieron claras las tareas porque eran sencillas. Medibles: todos alcanzaron el objetivo final. Acción: todos los equipos, salvo uno del grupo de la mañana, supieron localizar el lugar. Realistas: la actividad se pudo realizar sin problema a pesar de los obstáculos, si no conocían el lugar preguntaron. Tiempo: el máximo era una hora, pero el primer equipo del grupo de la tarde consiguió completar la meta en 15 minutos y el del grupo de la mañana en poco más de media hora.

d. ¿Ha habido algún conflicto? ¿Se ha resuelto? ¿Cómo?

En algunos equipos que se dividieron las tareas, hubo falta de comunicación. Para el único equipo que no localizó el lugar/objeto buscado el mayor problema que se creó entre ellos fue precisamente este. Por otra parte, los que tenían distinta opinión sobre el posible lugar, llegaron a un acuerdo.

e. Si repitiérais la actividad, ¿hubiéseis cambiado algo?

Algunos equipos se dieron cuenta que se hubiesen podido organizar de otra manera para cumplir mejor el objetivo. Por ejemplo, hacer un equipo más grande. De hecho, algunos de los equipos más numerosos pudieron dejar a uno de sus miembros en la Facultad, al que enviarle la fotografía del lugar/objeto localizado para que éste pudiera mostrársela al 
profesor sin tener que esperar al regreso de todo el equipo. Otros equipos que se dividieron inmediatamente para ir revisando edificios sin un análisis previo de lo que representaba la fotografía, se dieron cuenta de que perdieron mucho tiempo buscando en espacios equivocados. Del mismo modo, hubo grupos que se percataron que habían solicitado información a las personas incorrectas, lo que les hizo perder tiempo en la búsqueda. Según varios equipos este fue el mayor obstáculo que encontraron.

A los que no vieron necesidad de cambiar nada, se les hizo reflexionar sobre la necesidad del control, siempre viendo el lado positivo de los errores y de cómo ser consciente de ellos, por pequeños que sean, nos ayuda a mejorar. Incluso alguno de los equipos ganadores aceptó que, modificando algún aspecto de su planteamiento inicial, hubieran podido alcanzar antes el objetivo planteado. Además, siempre puede cambiar algún factor que hará que la situación no sea exactamente la misma.

Tras la actividad, se explican los conceptos básicos del tema a través del siguiente mapa mental (Figura 2). Se analiza el concepto de liderazgo, la diferencia entre grupos y equipos, el papel de los directivos en la administración pública y los principios de buen gobierno (de Miguel et al, 2017):

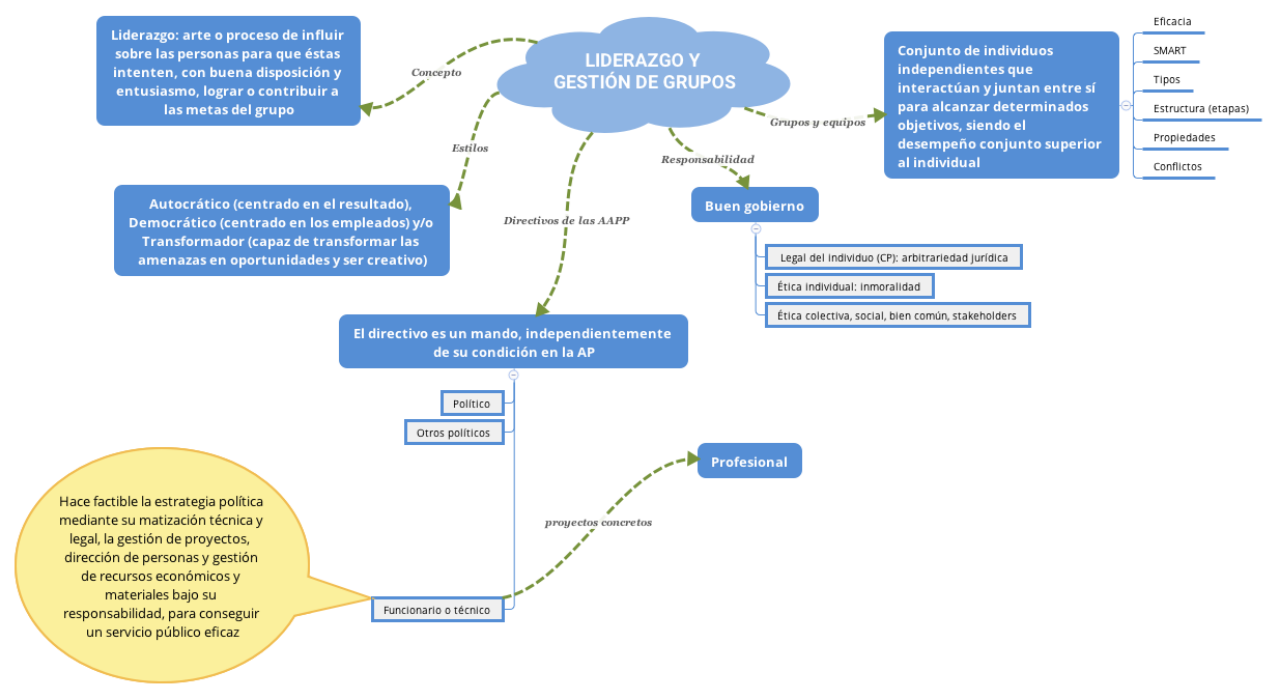

Fig. 2. Mapa mental del tema "Liderazgo y gestión de grupos". Fuente: de Miguel et al (2017), figura elaborada con Xmind

\section{Conclusiones}

El objetivo principal de la dinámica fue que los alumnos aprendiesen haciendo y, tras la actividad y el informe, comprendieron los conceptos de liderazgo y trabajo en equipo, así como la mejor manera de asignar tareas y aprovechar los recursos disponibles. Por otro lado, al plantear la dinámica como un juego, se sintieron muy motivados y siendo fuera del aula desarrollaron una mayor creatividad para cubrir el reto. 
Asimismo, se plantearon dos objetivos de aprendizaje específicos:

- Diferenciar un grupo de un equipo de trabajo. En el equipo, la suma de las capacidades individuales potenciales es superior al de la suma de sus miembros si trabajan de manera individual.

- Existen características que contribuyen a hacer eficaces a los equipos de trabajo. Evidentemente, y siguiendo a Robbins (2010), podemos detectar factores de contexto (recursos adecuados, liderazgo y estructura, clima de confianza y evaluación del desempeño, y sistema de recompensas), factores de composición (habilidades de los miembros, personalidad de los miembros, diversidad de los miembros, tamaño de los equipos y preferencias de los miembros del equipo), factores de diseño del trabajo (autonomía de los equipos, variedad de actividades y diversidad de habilidades, identidad de la tarea e importancia de la tarea) y factores de proceso (propósito común, metas específicas, eficiencia del equipo, niveles de conflicto y pereza social).

Por tanto, además de cumplir el objetivo de conocimiento, desarrollaron distintas competencias transversales como: aplicación y pensamiento práctico, análisis y resolución de problemas, creatividad, trabajo en equipo y liderazgo, y planificación y gestión del tiempo.

\section{Referencias}

CARABAL-MONTAGUD, M.A., SANTAMARINA CAMPOS, V., TARONCHER-BALLESTERO, J.M. \& DE-MIGUEL-MOLINA, M. (2018). "Reality Baths As a Pedagogical Strategy In University Education". En, 12th International Technology, Education and Development Conference (INTED 2018). Valencia: IATED. 2020-2027.

DE-MiguEl-MOLINA, M., ALBORS GARRIGOS, J., CERVELlO ROYO, R.E., DE MIGUEL MOLINA, B., SEGARRA-OÑA, M. \& PEIRO SIGNES, A. (2015). "Competencias transversales y Lego Serious Play: la necesidad de un enfoque adecuado”. En, Congreso Nacional de Innovación Educativa y Docencia en Red (IN-RED 2015). Valencia: Universitat Politècnica de València. 1-8.

DE-MIGUEL-MOLINA, M.; BAÑÓN GOMIS, A.J.; CATALÁ-PÉREZ, D. (2017). Management para las Administraciones públicas. Valencia: Editorial Universitat Politècnica de València.

DRUKER, P.F. (1954/2006), The practice of management, HarperCollins e-books.

FERNANDEZ SOLO DE ZALDIVAR, I. (2015). "Juego serio: gamificación y aprendizaje" en Comunicación y pedagogía: Nuevas tecnologías y recursos didácticos, 281, 43-48.

HINTHORNE, L.L. \& SCHNEIDER, K. (2012). "Playing with purpose: using serious play to enhance participatory development communication" en International Journal of Communication, 6 , 24.

LINDER, M.O., ROOS, J. \& VICTOR, B. (2001). "Play in organizations" en Working Paper 2. Imagination Lab.

ROBBINS, S.P. (2010). Introducción al comportamiento organizativo. Madrid: Pearson.

UNIVERSITAT POLITÈCNICA DE VALÈNCIA. Competencias Transversales. $<$ http://www.upv.es/contenidos/COMPTRAN/> [Consulta: 9 de marzo de 2019] 